\title{
Effect of Family Cohesion On Symptom Distress During Hematopoietic Stem Cell Transplantation
}

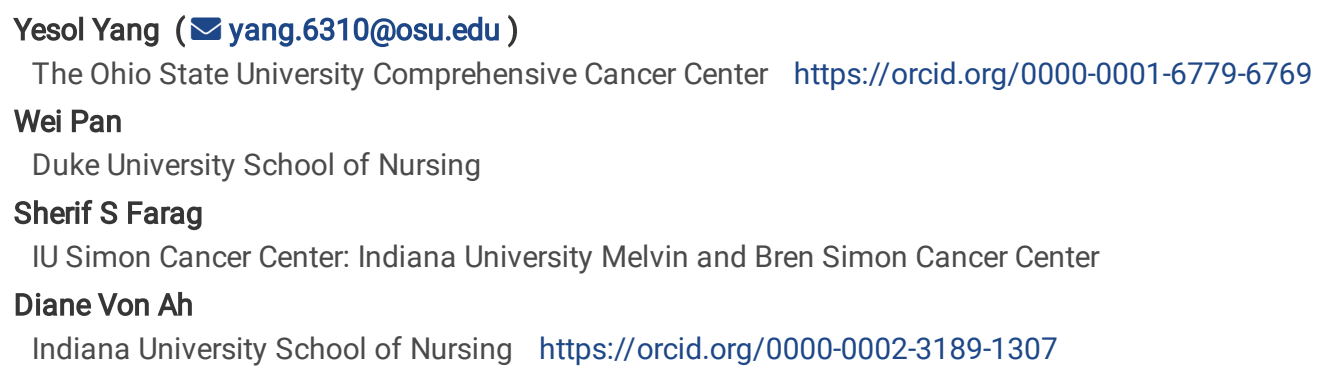

\section{Research Article}

Keywords: Hematopoietic stem cell transplantation, symptom distress, longitudinal parallel process, family cohesion, family functioning, cancer

Posted Date: June 3rd, 2021

DOI: https://doi.org/10.21203/rs.3.rs-499668/v1

License: (c) (i) This work is licensed under a Creative Commons Attribution 4.0 International License. Read Full License

Version of Record: A version of this preprint was published at Supportive Care in Cancer on September 28th, 2021. See the published version at https://doi.org/10.1007/s00520-021-06593-z. 


\section{Abstract}

Purpose: Family may play an important role in Hematopoietic stem cell transplantation (HSCT) recovery; however, little is known about the effect of family functioning on an individual's health. The purpose of this study was to examine the effect of family cohesion (family functioning) on the trajectory of HSCT recipients' symptom distress (symptom frequency and symptom bother) before, during, and after HSCT.

Methods: Secondary analysis was conducted using data collected from178 individuals who underwent HSCT. Longitudinal parallel-process (LPP) modeling was used to examine how family cohesion and HSCT associated symptoms (symptom frequency and symptom bother) change over time; and how these longitudinal changes relate to each other.

Results: The trajectory of family cohesion predicted the trajectories of HSCT associated symptom frequency and bother. HSCT recipients who experienced higher family cohesion at baseline ( $T 1)$ showed lower symptom frequency $(\mathrm{p}<.01)$ as well as symptom bother $(\mathrm{p}<.01)$ at $\mathrm{T} 1$. This trajectory analysis also showed that HSCT recipients who had improved family cohesion over time reported decrease in symptom frequency $(p<.01)$ as well as bother $(p<.01)$ over time.

Conclusion: Findings indicate that higher family cohesion predicts decrease in symptom distress over the HSCT trajectory. Interventions aimed at enhancing family cohesion have the potential to lower HSCT recipients' symptom distress. Further research is needed to understand the critical role of family cohesion and family functioning and their relationship with HSCT symptom distress prevention, early detection, and risk stratification.

\section{Introduction}

Hematopoietic stem cell transplantation (HSCT) remains the only curative option for many patients with hematological cancers [1] and a variety of non-neoplastic disorders [2]. However, this lifesaving treatment creates significant distress for those who receive HSCT [3]. HSCT recipients report physical, emotional, and social challenges before, during, and after transplant [4]. They experience psychological distress including uncertainty regarding health outcomes and/or isolation before and during hospitalization admitted for transplant. In addition, they also report unstable moods and physical distress including fatigue and/or pain throughout the course of transplant [5-7]. Consequently, this distress can diminish HSCT recipients' quality of life [6] and even increase their suicidal ideation [8].

To manage such distressing symptoms, HSCT recipients rely on their family (caregivers) for support and assistance [6]. Their family takes on caregiving responsibilities such as providing emotional support, assessing side-effects resulting from HSCT, ensuring adherence to medication regimens, and transporting the recipient for clinic appointments $[6,9]$. Due to these high caregiving responsibilities, some recipients experience conflict with family members [10]; however, others report enhanced emotional bonding with each of the family members throughout HSCT trajectories [11]. As such, family functioning may be altered, as they adapt to their new roles within the family unit.

Family functioning refers to structural and social properties of a family group, and this includes the pattern of interaction within the family $[12,13]$. Effective family functioning occurs with cohesion among members of family, while ineffective family functioning occurs with high level of conflict [14]. Based on Bronfenbrenner's social-ecological perspective, individual health can be influenced by the interaction between their immediate family environment (e.g., family functioning, specifically family cohesion) and their internal characteristics (e.g., biological and personal attributes) [15]. A large body of research supports this assertion by showing the influence of family conflicts (ineffective family functioning) on patient health outcomes. For example, patients who experience family conflict report an increased level of their depressive symptoms $[12,16]$.

In contrast to family conflict, family cohesion shows positive effects on patients' health outcomes. For example, when families display strong cohesion, pediatric patients manifest a positive adaptation to their medical illness [17], less behavioral and psychological problems [18], and resilience to the stress induced by HSCT [19]. Also, family cohesion has been reported as a protective factor against stressors including psychological distress [20]. Taken together, family cohesion appears to be associated with decreasing distress that HSCT recipients experience; however, to our knowledge, this effect has not been examined in the context of HSCT adult recipients.

Therefore, the purpose of this study was to examine the effects of family cohesion on the trajectory of HSCT recipients' symptom distress before, during, and after HSCT. Findings from this study are important for the development of evidence-based interventions to support transplant recipients and their families.

\section{Methods}

\section{Design and Sample}

This study was a secondary analysis of data from an American Cancer Society-funded longitudinal study that explored family adaptation to stress of HSCT $[10,21]$. Study participants included 178 individuals who underwent either an allogenic or autologous transplant. Eligibility criteria of participants were those who: 1) received a HSCT for the first time; and 2) were diagnosed with hematologic or lymphoid cancer such as leukemia, lymphoma, germ cell tumor, or multiple myeloma. The study was conducted at a National Cancer Institute-designated Comprehensive Cancer 
Center. All 178 HSCT patients were used for this analysis with data collected at six-time points: baseline, 1-2 week before hospitalization for HSCT (T1), during hospitalization for HSCT (T2), 1 month (T3), 4 months (T4), 8 months (T5), and 12 months (T6) following the initial hospital discharge for HSCT.

\section{Data collection and Measures}

A detailed procedure of data collection was reported in the previously published studies [10, 21]. Briefly, first-time recipients for allogeneic or autologous transplant and their families that were interested in the original study to examine family adaptation and stress of HSCT were referred from their healthcare provider to participate. HSCT recipients were provided information regarding the study in-person or over the phone as well as provided all study details in writing. Survey data from HSCT recipients consenting to participate in the study were used in this analysis.

Self-report questionnaires were completed by each participant at six-time points. The instruments included demographic questionnaires, family cohesion, and HSCT symptom checklist including symptom frequency and symptom bother. Demographic questionnaires included recipients' age, race/ethnicity, gender, education, marital status, employment status, diagnosis, and date and type of HSCT. Family cohesion was measured by the Moos Family environment sub-scale of cohesion. This is a 9-item subscale ranging 0-9, with higher score indicating greater cohesion. Cronbach's alpha of family cohesion is 0.78 [9]. Symptom frequency and Symptom Bother were measured by the HSCT symptom checklist which includes 16 prevalent cancer symptoms ranging from physical symptoms to social/psychologic symptoms [5]. Physical symptoms include nausea, vomiting, mouth pain, difficulty swallowing, diarrhea, decreased appetite, fever, headache, nosebleed, difficulty sleeping, pain, hair loss; psychosocial symptoms include boredom, tiredness, isolation, loneliness [5]. Participants were asked to indicate on a five-point scale how frequently they experience each of these symptoms (i.e., symptom frequency) and how much those symptoms bother their everyday living (i.e., symptom bother). The sum of items scores for each subscale (symptom frequency and symptom bother) ranges from 16 to 80 , with higher scores indicating more frequent symptom and greater bother. Cronbach's alphas of symptom frequency and symptom bother are 0.81 and 0.80 , respectively.

\section{Statistical Analysis}

Descriptive statistics were computed for sample characteristics and longitudinal variables (symptom distress-frequency and bother, and family cohesion). Longitudinal parallel-process (LPP) modeling was used for data analysis [22, 23]. The LPP is a type of growth curve modeling that combines multilevel modeling (MLM) and structural equation modeling (SEM). This two-step approach allows examination of the relationships between two (or more) different longitudinal processes at the same time. This provides insight into how family cohesion and HSCT associated symptoms (symptom frequency and symptom bother) change over time; and how these longitudinal changes relate to each other.

In the first step of the LPP modeling, the initial status at T1 (intercept) and the change over time (slope) of each variable (family cohesion, symptom frequency, and symptom bother) were estimated separately by using MLM with SAS Proc Mixed. In this step, we treated HSCT recipients' age and type of HSCT (allogeneic vs autologous) as covariates because much of the literature agreed on age as well as HSCT type as strong predictors of HSCT-associated symptom distress [4, 7, 24-25]. SEM was then used in the second step to examine the effects of the trajectory (characterized by the intercept and slope) of family cohesion on the trajectories of both symptom frequency and bother using IBM SPSS AMOS. The SEM fit was evaluated using the model-fit indices of Chi-square of the estimated model ( $\chi 2)$, root mean square error of approximation (RMSEA), goodness of fit index (GFI), normed fit index (NFI), incremental fit index (IFI), relative fit index (RFI), and comparative fit index (CFI). A nonsignificant Chi-square value ( $p>.05$ ) suggests a good overall model fit to the data. GFI $\geq 0.90, \mathrm{NFI} \geq 0.90, \mathrm{IFI}>0.90, \mathrm{RFI}>0.90, \mathrm{CFI}>0.90$, and RMSEA $\leq 0.08$ indicate an adequate fit [26]. The MLM approach in the first step automatically handled missing data issues. Missing values were also found to be missing at random, thus having no negative effect on parameter estimation [27].

\section{Results}

\section{Description of Sample Characteristics}

The majority of patients were male (70.8\%), white (90\%), and married (93\%). Patients in this study were on average $51.7(\mathrm{SD}=12.00)$ years of age, worked full-time (41.2\%) and had at least a high school education (98\%). In addition, patients who participated in this study were primarily treated with autologous transplant (78.7\%). Detailed demographic and clinical information of patients was summarized in Table 1. 
Table 1

Description of Sample Characteristics

\begin{tabular}{|c|c|}
\hline \multicolumn{2}{|l|}{ Patient demographic $(\mathrm{N}=178)$} \\
\hline Age (years) & Mean (SD) \\
\hline & $51.74(12.00)$ \\
\hline \multicolumn{2}{|l|}{ Gender } \\
\hline Male & $126(70.8 \%)$ \\
\hline Female & $52(29.2 \%)$ \\
\hline Race/Ethnicity & $\mathbf{n}$ \\
\hline White & $160(89.9 \%)$ \\
\hline Black or African American & $8(4.5 \%)$ \\
\hline American Indian/Alaska Natives & $2(1.1 \%)$ \\
\hline More than one race & $7(4.0 \%)$ \\
\hline Missing & $1(0.5 \%)$ \\
\hline Marital status & n (\%) \\
\hline Married & $166(93.3 \%)$ \\
\hline Living with Partner & $9(5.1 \%)$ \\
\hline Divorced & $2(1.1 \%)$ \\
\hline Widowed & $1(0.5 \%)$ \\
\hline Employ status & n (\%) \\
\hline Full-time & $70(39.3 \%)$ \\
\hline Part-time & $8(4.5 \%)$ \\
\hline Unemployed & $12(6.7 \%)$ \\
\hline Disabled & $44(24.7 \%)$ \\
\hline Retired & $34(19.1 \%)$ \\
\hline Homemaker & $2(1.1 \%)$ \\
\hline Missing & $8(4.5 \%)$ \\
\hline Education & n (\%) \\
\hline Eight grade or less & $2(1.1 \%)$ \\
\hline High school & $57(32.0 \%)$ \\
\hline Vocational/ technical school & $20(11.2 \%)$ \\
\hline Some college & $40(22.4 \%)$ \\
\hline Four-year college & $34(19.1 \%)$ \\
\hline Graduate degree & $19(10.7 \%)$ \\
\hline Missing & $6(3.5 \%)$ \\
\hline Types of HSCT & n (\%) \\
\hline Autologous & $140(78.7 \%)$ \\
\hline Allogeneic & $38(21.3 \%)$ \\
\hline
\end{tabular}

\section{Description of longitudinal variables}

The means and standard deviations of symptom distress (frequency and bother) and family cohesion across the six time points are seen in Table 2. Regardless of HSCT group, patients in both groups demonstrated a peak symptom distress (symptom frequency and bother) at T2 before it decreased at the later time points. Also, patients in the autologous group showed a higher level of symptom distress at early phase ( $\mathrm{T} 1$ and $\mathrm{T} 2)$, 
whereas patients in the allogenic group showed a higher level of symptom distress at later phase $(\mathrm{T} 3, \mathrm{~T} 4, \mathrm{~T} 5$, and T6). There are no differences in family cohesion in both groups over time. Also, there are no significant differences in symptom frequency as well as bother over time between two groups (autologous and allogenic; all $p>0.05)$ except for symptom frequency at T3 $(p<0.01)$.

Table 2

Description of Longitudinal Variables by Time and HSCT Type $(\mathrm{N}=178)$

\begin{tabular}{|c|c|c|c|c|c|c|c|c|c|c|c|c|c|c|c|c|c|c|}
\hline \multicolumn{19}{|c|}{ Autologous } \\
\hline & \multicolumn{3}{|l|}{$\mathrm{T} 1$} & \multicolumn{3}{|l|}{ T2 } & \multicolumn{3}{|l|}{ T3 } & \multicolumn{3}{|l|}{$\mathrm{T} 4$} & \multicolumn{3}{|l|}{ T5 } & \multicolumn{3}{|l|}{ T6 } \\
\hline & $\mathrm{n}$ & $M$ & SD & $\mathrm{n}$ & $M$ & SD & $\mathrm{n}$ & $M$ & SD & $\mathrm{n}$ & $M$ & SD & $n$ & M & SD & $\mathrm{n}$ & M & SD \\
\hline $\begin{array}{l}\text { Symptom } \\
\text { distress }\end{array}$ & 139 & 31.2 & 7.8 & 135 & 41.5 & 9.5 & 30.8 & 28.2 & 7.2 & 130 & 25.9 & 8.4 & 120 & 24.8 & 8.2 & 117 & 24.0 & 8.5 \\
\hline \multicolumn{18}{|l|}{ Frequency } & 8.6 \\
\hline \multicolumn{19}{|l|}{ - Bother } \\
\hline $\begin{array}{l}\text { Family } \\
\text { cohesion }\end{array}$ & 136 & 7.7 & 1.7 & 130 & 7.7 & 1.5 & 128 & 7.7 & 1.5 & 130 & 7.7 & 1.5 & 119 & 7.7 & 1.7 & 117 & 7.8 & 1.7 \\
\hline \multicolumn{19}{|l|}{ Allogeneic } \\
\hline & \multicolumn{3}{|l|}{$\mathrm{T} 1$} & \multicolumn{3}{|l|}{ T2 } & \multicolumn{3}{|l|}{ T3 } & \multicolumn{3}{|l|}{$\mathrm{T} 4$} & \multicolumn{3}{|l|}{ T5 } & \multicolumn{3}{|l|}{ T6 } \\
\hline & $\mathrm{n}$ & M & SD & $n$ & M & SD & $\mathrm{n}$ & $M$ & SD & $\mathrm{n}$ & M & SD & $\mathrm{n}$ & M & SD & $\mathrm{n}$ & M & SD \\
\hline $\begin{array}{l}\text { Symptom } \\
\text { distress }\end{array}$ & 37 & 26.6 & 8.0 & 34 & 39.2 & 9.4 & 27 & 31.9 & 10.8 & 26 & 29.5 & 7.9 & 22 & 27.8 & 9.7 & 19 & 26.3 & 8.8 \\
\hline \multicolumn{18}{|l|}{ Frequency } & 9.5 \\
\hline \multicolumn{19}{|l|}{ - Bother } \\
\hline $\begin{array}{l}\text { Family } \\
\text { cohesion }\end{array}$ & 37 & 7.4 & 1.5 & 34 & 7.7 & 1.6 & 27 & 7.7 & 1.6 & 26 & 7.7 & 1.7 & 22 & 7.2 & 2.4 & 19 & 7.1 & 2.5 \\
\hline
\end{tabular}

\section{Associations between Trajectories of Family Cohesion and Symptom Trajectories}

The SEM model had an adequate fit of data with chi-square $\left(\chi^{2}=5.39, \mathrm{p}=0.37\right)$, normed fit index $(\mathrm{NFI})=1.00$, comparative fit index $(\mathrm{CFI})=1.00$, and root-mean-square error of approximation (RMSEA) $=0.02$ (Fig. 1). As seen in Fig. 1, family cohesion at T1 (intercept) had a direct relationship with symptom bother at T1 (intercept; $\beta=-.21, \mathrm{p}<.01$ ) and over time (slope; $\beta=.09, \mathrm{p}<.01$ ). Family cohesion at T1 (intercept) was also associated with symptom frequency at T1 (intercept; $\beta=-.18, \mathrm{p}<.01$ ), but not over time. Lastly, family cohesion over time (slope) was associated with the slopes of symptom bother $(\beta=-.15, p<.01)$ and symptom frequency $(\beta=-.15, p<.01)$.

\section{Discussion}

To our knowledge, this is the first study to apply the longitudinal parallel-process (LPP) to the analysis of longitudinal associations between family cohesion and symptom trajectories in HSCT adult recipients. From the results, we can broadly conclude that the trajectory of family cohesion predicted the trajectories of HSCT associated symptom distress. This LPP approach is critical for this analysis as this provides insight into how symptom distress changes over the trajectory of HSCT and how these changes are influenced by the changes in family cohesion. The obtained findings using this LPP method suggests that appropriate intervention for enhanced family cohesion has the potential to lower HSCT recipients' symptom distress.

For HSCT recipients who experienced higher quality of family cohesion at baseline (T1), their initial symptom bother was lower than those with lower family cohesion. This suggests that family cohesion may be an important factor for cancer patients pre-HSCT. Similarly, we also found that those recipients with higher quality of family cohesion at T1 also experienced a lower initial symptom frequency. This finding is consistent to previous research that has shown that family cohesion may reduce psychological distress [20], and indirectly reduce anxiety and depression in healthy adults and adolescents [28]. Researchers have also noted that family cohesion played an important role in health-related quality of life in the spouses of cancer survivors. In a study of 91 breast, colorectal and prostate cancer patients and their spouses, healthy family communication mediated the impact between family cohesion and physical health-related quality. This work indicates that implementing interventions to promote family communication and family cohesion may have beneficial effects for families experiencing cancer [29].

Our analyses also indicated that family cohesion at T1 was not associated the degree of symptom frequency over time but was slightly related to symptom bother overtime. It is possible that recipients sustained high level of symptom frequency over time without showing changes, thus failing 
to establish association with initial family cohesion. In addition, the level of symptom bother may also be attributed to severe complications that often occur with the course of HSCT such as Graft versus host disease (GVHD) [4]. HSCT recipients often suffer from distressing symptoms over the course of treatment (transplant) and therefore, baseline scores of family cohesion may not be the most robust indicator of those who will have higher levels of bothersome symptoms. Future studies should evaluate how HSCT recipients' symptom frequency and bother changes over time and how these changes are associated with initial quality of family cohesion.

In examining family cohesion over time, it was clear that those who experienced greater family cohesion (slope), the severity of their HSCT symptom bother as well as their symptom frequency decreased over time. This finding is in line with previous literature showing that family is a direct and important individuals' social environment that affects their health [30, 31]. HSCT recipients living within a healthy family dynamic (i.e., family cohesion) would receive strong family support that may be helpful to deal with their symptom distress, which in turn will contribute to a faster resolution of their health problems. This understanding will be foundational knowledge when developing interventions to improve symptom distress in HSCT recipients. For example, it would be useful to assist the recipients to seek sources of support and to help them how to cope when the family cohesion is not optimal.

To date, most interventions for those with symptom distress are primarily focusing on managing their internal clinical characteristics. A review of the empirical literature revealed that physical exercise is an effective intervention in alleviating HSCT associated physical and psychological symptom distress [32]. Based on the obtained findings from this study, it would be needed to develop family intervention with the aim of lowering their symptom distress as well as improving their family members' well-being. For example, family-based group tasks that help improve family cohesion can be provided to HSCT recipients' family members [33] as a part of the intervention for improving HSCT associated symptom distress.

Therefore, assessing whether or not the family has high cohesion is critical to symptom distress prevention, early detection, and risk stratification. Systematic assessments of family environment are not typically performed in clinical settings; thus, health professionals may be missing opportunities to offer supportive intervention to their family members. If health professionals intervene to enhance family cohesion, this may contribute to improvement in family well-being, and also the symptom distress of HSCT recipients.

\section{Strengths and Limitations of the Study}

Several strengths of this study should be noted. First this is one of the few studies that examines the experience of HSCT patients over the trajectory of care. This longitudinal approach allowed for modeling of factors over time and identifying the role of the family and family cohesion on symptom frequency and bother in HSCT recipients. Results should be also examined in light of some limitations of this study. This study was a secondary analysis of existing data and therefore, additional family or other symptoms could not be added. In addition, the sample was homogenous in terms of sociodemographic and clinical diversity, which may impede the generalizability of the study findings. Future research is needed that includes large heterogeneous sample to represent HSCT population.

\section{Conclusion}

Despite these limitations, this study is the first to examine the effects of family cohesion on the trajectory of HSCT-associated symptom distress. Our findings suggest that family cohesion is helpful to predict the trajectory of HSCT-associated symptom distress. Thus, it heightens the necessity of developing family-centered intervention aimed at improving HSCT-associated symptom distress as well as family functioning (family cohesion).

\section{Declarations}

Funding: A grant from the American Cancer Society (RSGPB-05-012-01-CPPB) supported this research. The content in this paper is solely the responsibility of the authors and does not necessarily represent the official views of the funding agencies.

Conflicts of interest: The authors declare that they have no conflict of interest.

Availability of data and material: Data will be provided to the publisher after they obtain a material transfer agreement from the Indiana University School of Nursing

Code availability: Not applicable.

Authors' contributions: All authors were involved in writing.

Ethical approval: This study was approved by the committee on Human research at the Indiana University School of Nursing.

Consent to participate: All of the patients signed a written informed consent prior to study participation.

Consent for publication: All of the authors read the final version of the paper and approved its submission for publication.

\section{Acknowledgments}


The authors thank the participating families for sharing their experiences with us. We would also like to thank Dr. Betsy Fife original PI on the American Cancer Society grant that made this work possible.

\section{References}

1. Wildes TM, Stirewalt DL, Medeiros B, Hurria A (2014) Hematopoietic stem cell transplantation for hematologic malignancies in older adults: geriatric principles in the transplant clinic. J Natl Compr Canc Netw 12(1):128-136. doi:10.6004/jnccn.2014.0010

2. Resnick IB, Shapira MY, Slavin S (2005) Nonmyeloablative stem cell transplantation and cell therapy for malignant and non-malignant diseases. Transpl Immunol 14(3-4):207-219. doi:10.1016/j.trim.2005.03.009

3. Gooley TAP, Chien JWMD, Pergam SAMDMPH, Hingorani SMDMPH, Sorror MLMD, Boeckh MMD,... McDonald GBMD (2010) Reduced Mortality after Allogeneic Hematopoietic-Cell Transplantation. The New England Journal of Medicine 363(22):2091-2101. doi:http://dx.doi.org/10.1056/NEJMoa1004383

4. Bevans MF, Mitchell SA, Marden S (2008) The symptom experience in the first 100 days following allogeneic hematopoietic stem cell transplantation (HSCT). Supportive care in cancer: official journal of the Multinational Association of Supportive Care in Cancer 16(11):12431254. doi:10.1007/s00520-008-0420-6

5. Fife BL, Huster GA, Cornetta KG, Kennedy VN, Akard LP, Broun ER (2000) Longitudinal study of adaptation to the stress of bone marrow transplantation. J Clin Oncol 18(7):1539-1549. doi:10.1200/jco.2000.18.7.1539

6. Sannes TS, Simoneau TL, Mikulich-Gilbertson SK, Natvig CL, Brewer BW, Kilbourn K, Laudenslager ML (2019) Distress and quality of life in patient and caregiver dyads facing stem cell transplant: identifying overlap and unique contributions. Supportive care in cancer: official journal of the Multinational Association of Supportive Care in Cancer 27(6):2329-2337. doi:10.1007/s00520-018-4496-3

7. Mosher CE, Redd WH, Rini CM, Burkhalter JE, DuHamel KN (2009) Physical, psychological, and social sequelae following hematopoietic stem cell transplantation: a review of the literature. Psycho-oncology 18(2):113-127. doi:10.1002/pon.1399

8. Tichelli A, Labopin M, Rovó A, Badoglio M, Arat M, van Lint MT,.. . Socié G (2013) Increase of suicide and accidental death after hematopoietic stem cell transplantation: a cohort study on behalf of the Late Effects Working Party of the European Group for Blood and Marrow Transplantation (EBMT). Cancer 119(11):2012-2021. doi:10.1002/cncr.27987

9. Fife BL, Von Ah DM, Spath ML, Weaver MT, Yang Z, Stump T, Farag S (2017) Preliminary efficacy of a brief family intervention to prevent declining quality of life secondary to parental bone marrow transplantation. Bone Marrow Transplant 52(2):285-291. doi:10.1038/bmt.2016.267

10. Fife BL, Monahan PO, Abonour R, Wood LL, Stump TE (2009) Adaptation of family caregivers during the acute phase of adult BMT. Bone Marrow Transplant 43(12):959-966. doi:10.1038/bmt.2008.405

11. Packman W, Weber S, Wallace J, Bugescu N (2010) Psychological effects of hematopoietic SCT on pediatric patients, siblings and parents: a review. Bone Marrow Transplant 45(7):1134-1146. doi:10.1038/bmt.2010.74

12. Lewandowski AS, Palermo TM, Stinson J, Handley S, Chambers CT (2010) Systematic review of family functioning in families of children and adolescents with chronic pain. The journal of pain: official journal of the American Pain Society 11(11):1027-1038. doi:10.1016/j.jpain.2010.04.005

13. Epstein NB, Baldwin LM, Bishop DS (1983) The McMaster family assessment device. Journal of Marital Family Therapy 9(2):171-180. doi:https://doi.org/10.1111/j.1752-0606.1983.tb01497.x

14. Alderfer MA, Fiese BH, Gold JI, Cutuli JJ, Holmbeck GN, Goldbeck L,.. . Patterson J (2008) Evidence-based assessment in pediatric psychology: family measures. J Pediatr Psychol 33(9):1046-1061. doi:10.1093/jpepsy/jsm083 discussion 1062 - 1044.

15. Bronfenbrenner U (1977) Toward an experimental ecology of human development. Am Psychol 32(7):513-531. doi:10.1037/0003066X.32.7.513

16. Dunbar SB, Clark PC, Quinn C, Gary RA, Kaslow NJ (2008) Family influences on heart failure self-care and outcomes. J Cardiovasc Nurs 23(3):258-265. doi:10.1097/01.JCN.0000305093.20012.b8

17. Holmes CS, Yu Z, Frentz J (1999) Chronic and discrete stress as predictors of children's adjustment. J Consult Clin Psychol 67(3):411-419. doi:10.1037//0022-006x.67.3.411

18. Jobe-Shields L, Alderfer MA, Barrera M, Vannatta K, Currier JM, Phipps S (2009) Parental depression and family environment predict distress in children before stem cell transplantation. Journal of developmental behavioral pediatrics: JDBP 30(2):140-146. doi:10.1097/DBP.0b013e3181976a59

19. Phipps S, Mulhern RK (1995) Family cohesion and expressiveness promote resilience to the stress of pediatric bone marrow transplant: a preliminary report. Journal of developmental and behavioral pediatrics: JDBP, 16(4): 257-263. Retrieved from http://europepmc.org/abstract/MED/7593661

20. Rivera Fl, Guarnaccia PJ, Mulvaney-Day N, Lin JY, Torres M, Alegria M (2008) Family Cohesion and its Relationship to Psychological Distress among Latino Groups. Hispanic journal of behavioral sciences 30(3):357-378. doi:10.1177/0739986308318713

Page $7 / 8$ 
21. Spath ML, Fife BL, Monahan PO, Decker CL, Austin JK, Abonour R, Wood LL (2013) Children's emotional adaptation to parental BMT. Bone Marrow Transplant 48(1):135-140. doi:10.1038/bmt.2012.93

22. Sousa KH, Kwok O-M, Schmiege SJ, West SG (2013) A Longitudinal Approach to Understanding the Relationship Between Symptom Status and QOL. West J Nurs Res 36(6):732-747. doi:10.1177/0193945913510980

23. Cheong J, Mackinnon DP, Khoo ST (2003) Investigation of Mediational Processes Using Parallel Process Latent Growth Curve Modeling. Struct Equ Modeling 10(2):238. doi:10.1207/s15328007sem1002_5

24. Hefner J, Kapp M, Drebinger K, Dannenmann A, Einsele H, Grigoleit GU,.. . Mielke S (2014) High prevalence of distress in patients after allogeneic hematopoietic SCT: Fear of progression is associated with a younger age. Bone Marrow Transplant 49(4):581-584. doi:10.1038/bmt.2013.228

25. Popplewell LL, Forman SJ (2002) Is there an upper age limit for bone marrow transplantation? Bone Marrow Transplant 29(4):277-284. doi:10.1038/sj.bmt.1703382

26. Hu Lt, Bentler PM (1999) Cutoff criteria for fit indexes in covariance structure analysis: Conventional criteria versus new alternatives. Structural Equation Modeling: A Multidisciplinary Journal 6(1):1-55. doi:10.1080/10705519909540118

27. Little RJA, Rubin DB (2002) Statistical analysis with missing data (2nd Ed.). Hooken, NJ

28. Anyan F, Hjemdal O (2018) Stress of home life and gender role socializations, family cohesion, and symptoms of anxiety and depression. Women Health 58(5):548-564. doi:10.1080/03630242.2017.1316343

29. Lim J-W, Shon E-J (2018) The Dyadic Effects of Family Cohesion and Communication on Health-Related Quality of Life: The Moderating Role of Sex. Cancer nursing 41(2):156-165. doi:10.1097/NCC.0000000000000468

30. Keitner GI, Ryan CE, Miller IW, Kohn R, Bishop DS, Epstein NB (1995) Role of the family in recovery and major depression. Am J Psychiatry 152(7):1002-1008. doi:10.1176/ajp.152.7.1002

31. Goodyer IM, Herbert J, Tamplin A, Secher SM, Pearson J (1997) Short-term outcome of major depression: II. Life events, family dysfunction, and friendship difficulties as predictors of persistent disorder. J Am Acad Child Adolesc Psychiatry 36(4):474-480. doi:10.1097/00004583199704000-00009

32. Jafari H, Jannati Y, Nesheli H, Hassanpour S (2017) Effects of nonpharmacological interventions on reducing fatigue after hematopoietic stem cell transplantation. Journal of Research in Medical Sciences, 22(13)

33. Rediy S, Tefera B (2020) A Family-Based Behavioral Intervention to enhance Family Communication and Family Cohesion among Siblings in Polygamous Family

\section{Figures}

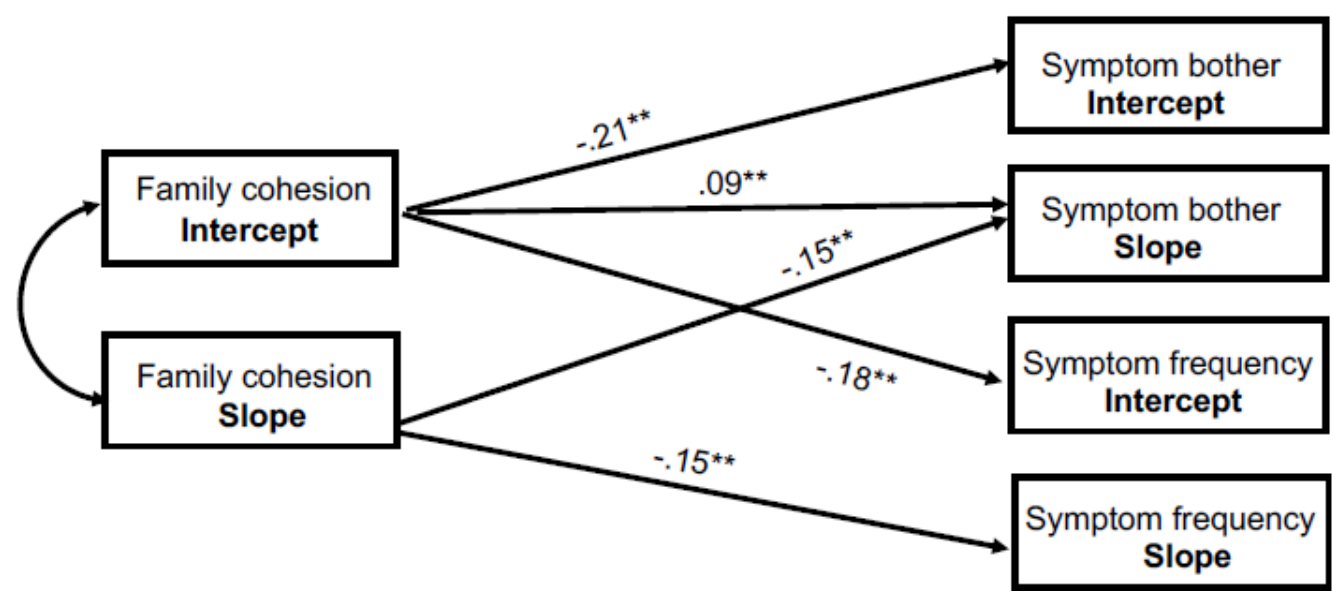

Chi-square $(4)=5.39, p=.37 ;$ RMSEA $=.02$

$\mathrm{GFI}=.99, \mathrm{NFI}=.99, \mathrm{IFI}=1.00, \mathrm{RFI}=.98, \mathrm{CFI}=1.00$

Note: ${ }^{\star} p<.05 .{ }^{* \star} p<.01$

\section{Figure 1}

Longitudinal parallel process model with standardized estimates describing the associations between the trajectory of family cohesion and the trajectories of symptom frequency and bother (The error terms of endogenous variables and their correlations were omitted for clarity) 